\title{
EXTRAcción Y USO dE LA ARCILLA POR ALfareros TRADICIONALES
}

\author{
"Lo importante cuando se crea una pieza no es \\ la decoración sino la forma, ésta sustenta todo lo demás".
}

Francisco Hernández. Artesano

\begin{abstract}
Resumen
El artículo presenta la labor de manufactura de piezas artesanales, desde el proceso de extracción de arcilla hasta la elaboración de la cerámica, por parte de dos artesanos oriundos de Santa Ana y de Jaris de Mora, cantones de la provincia de San José, Costa Rica. Se pretende mostrar cómo la labor de los artesanos es un compendio de conocimiento de generación a generación que se mantiene hasta nuestros días.
\end{abstract}

Palabras claves: artesanos, artesanías, arcilla, manufactura tradicional.

\begin{abstract}
This paper presents the handcrafting process of ceramic artifacts, from the clay extraction to the development of a complete piece, as made by two native artisans from Santa Ana and Jaris de Mora, counties of San José, Costa Rica. It aims to show how the work of a craftsman is a compendium of knowledge, that is passed from generation to generation, and that still continues today.
\end{abstract}

Keywords: artisans, crafts, clay, traditional manufacturing.

\section{Consideraciones iniciales}

Carolina Cavallini Morales. Máster en Antropología con énfasis en Arqueología. Profesora interina en la Escuela de Antropología. Interesada en proceso de manufactura cerámica precolombina, de sociedades complejas, arqueología colonial y etnohistoria. cavalliniorama@gmail.com

Desde el inicio de la humanidad, el ser humano se ha distinguido por la utilización de su entorno natural para la creación de objetos que le permitan un mayor grado de bienestar. El ser humano fue capaz de crear un sinnúmero de bienes que con el paso del tiempo le permitieron desarrollar una habilidad innata para la escogencia tanto de las materias primas como la destreza para conformarlas en un artefacto nuevo y diferente; es así que, desde estas tradiciones milenarias, los artesanos modernos conservan la pericia de la transformación. En sus manos se reflejan las huellas de una vida dedicada al constante cambio y en sus talleres se manifiesta un proceso de enseñanza de varios años. 
En la actualidad, el gremio de artesanos se distingue por la variedad de materiales con que trabaja: cuero, arcilla, cestería, madera, hierro, tejidos, plástico, papel y pintura, por citar algunos. A partir de las características de creación del producto, el uso de materia prima y la forma de elaboración, las artesanías se distinguen por ser tradicionales o de nuevas tendencias (neoartesanías). Las primeras, conservan una producción más apegada a técnicas que han pasado de generación a generación; las segundas, corresponden a productos que conservan diseños y técnicas tradicionales pero la materia prima es modificada, por ejemplo la creación artesanal de papel o bisutería (Chang, 2008). Asimismo, es importante anotar que, aunque una artesani sea considerada tradicional y exista en el territorio nacional gran variedad de artifices, las artesanías como tales nunca son iguales, si bien se utiliza el mismo material, cada una esá impregnada de la vivencia del artesano, su entorno y experiencia personal.

Para el caso que concierne a este trabajo, nos centraremos en la experiencia de artesanos alfareros de Santa Ana, cantón número nueve, y Jaris de Mora cantón número siete, de San Jose. El presente estudio surgió como una inquieceramistas tradicionales. De igual manera, este ejercicio es en cierta forma un entendimiento del proceso complejo de la formación de una vasija o cua un otro enser.

\section{Antecedentes}

En la Colonia, la alfarería española se encontró con los ceramistas nativos de América, de ahí que las producciones artísticas posteriores conllevaron un sincretismo entre los dos mundos que, en ocasiones, fue más una forma de opresión y de cambio de las sociedades. El principal cambio introducido por los nuevos alfareros en América fue el torno de pie aunque se tiene conocimiento que entre los mayas (3000 a.C.) se utilizaba una herramienta llamada kabal, que hacía de un torno falso; este "aparato era cilíndrico [ .. ] descansaba sobre una base plana y que el alfarero "aptení con sus pies" (Neff, 1990, p.17). Sin emna base torno introducido produjo una nueva forma (Neff, 1990, p.17). Sin embargo, el muchas de las técnicas precolombinas tradicionales.

La alfarería para el siglo XVI se distinguió por la creación de objetos que suplieran necesidades cotidianas, como utensilios de cocina o de acarreo de agua. Ya entrado el siglo XVII, la alfarería se centró más en la elaboración de tejas y ladrillos, labor que se desarrolló más en la ciudad de Cartago y se acrecentó por el desarrollo de los pueblos (Payne, 2000). En los talleres cartagineses, donde se efectuaban estos productos, era común. jóvenes aprendices, y, por supuesto, la arcilla extraída de lugares aledaños a localidad del taller alfarero. El ceramista y sus creaciones respondían a un aso más cotidiano, su posición en ese entonces era más hacia un servicio indispensable que tenía gran demanda.

En los textos sobre la historia artesanal de los siglos XVIII, XIX y XX, la labor alfarera no se rescata a profundidad; aunque su temática gira alrededor de los artesanos, en los textos se analizan otros artífices desde perspectivas económicas o políticas en cuanto a sus gremios y su producción (Oliva, 1985; Rodríguez, 1993; Benavidez, 2004).

\section{Método de extracción y preparación de la arcilla}

El trabajo de campo de donde se obtuvo esta información corresponde a visitas a cuatro talleres de artesanos en Santa Ana y Jaris, en el cantón de Mora, por ser este último donde se ubica un yacimiento de arcilla blanca, conocida como caolin". Para efectos de información, en este trabajo se toman como eje las visitas tajo en Jaris.

\section{Método de extracción}

La selección y extracción de la arcilla son procedimientos esenciales para los artesanos alfareros, ya que de esto depende la posterior creación de las piezas. Una arcilla con impurezas por su mal manejo, entorpece una pieza de buena calidad. En esta oportunidad, se visitaron dos yacicica

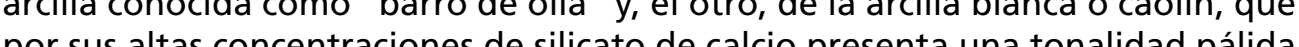
que conserva incluso después del horneado. El yacimiento de arcilla blanca se que conserva incluso despues del hom enculra El taller de extracción de arcilla está ubicado muy cerca del yacimiento de la materia prima por lo gen de arcilla está ubicado mu cerca del yacimiento de la materia prima, por lo general, es posible ver pallas y especies de camas de ladrillo o tas simples: tablones para revolver las mezclas, palas, mangueras o dubetas para tas simples. tablones para répices, hilos gruesos para coser, paletas de plástico, etc. la mayorí a claje de objetos cotidianos o que incluso pueden ser considerados como desecho.

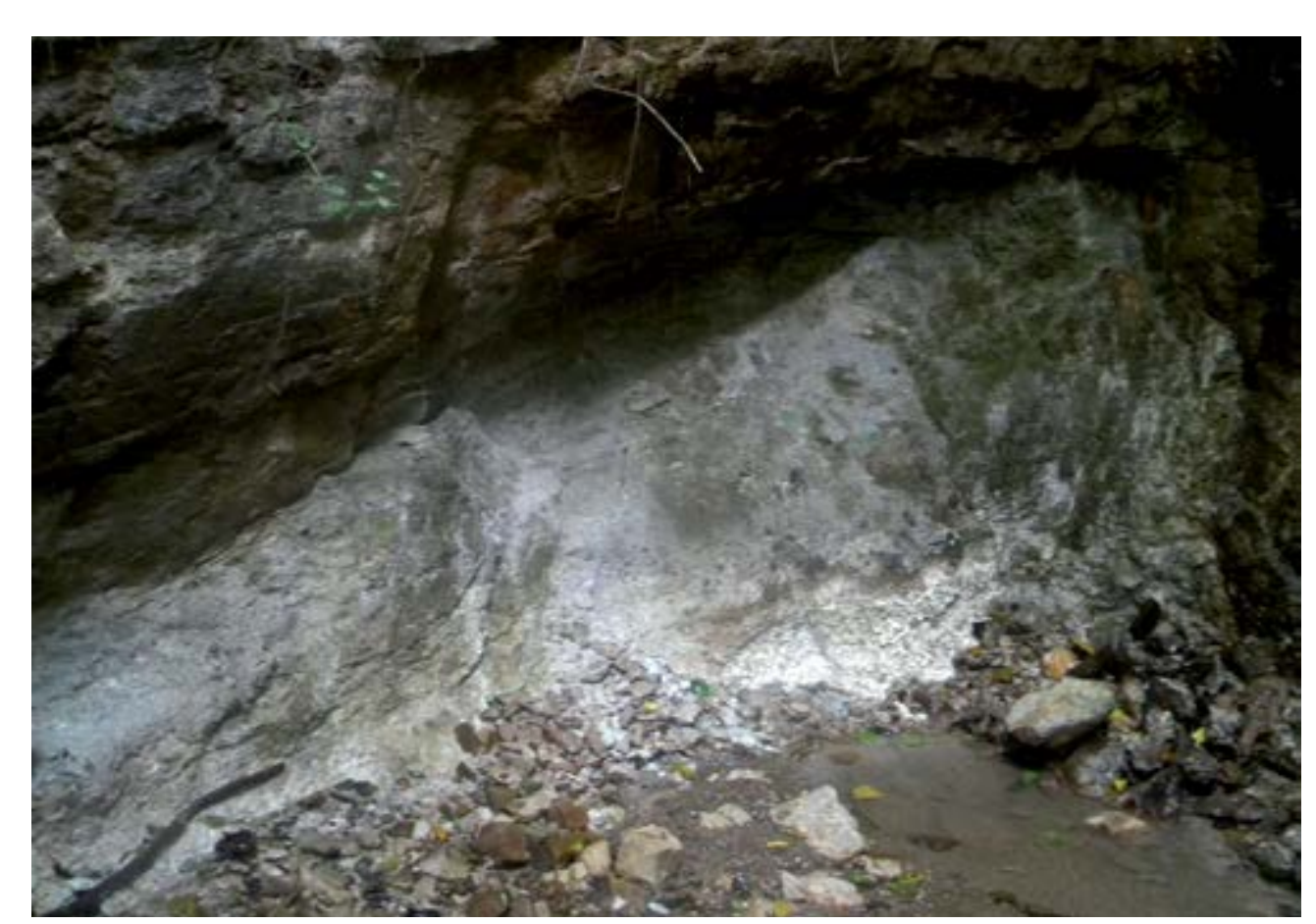



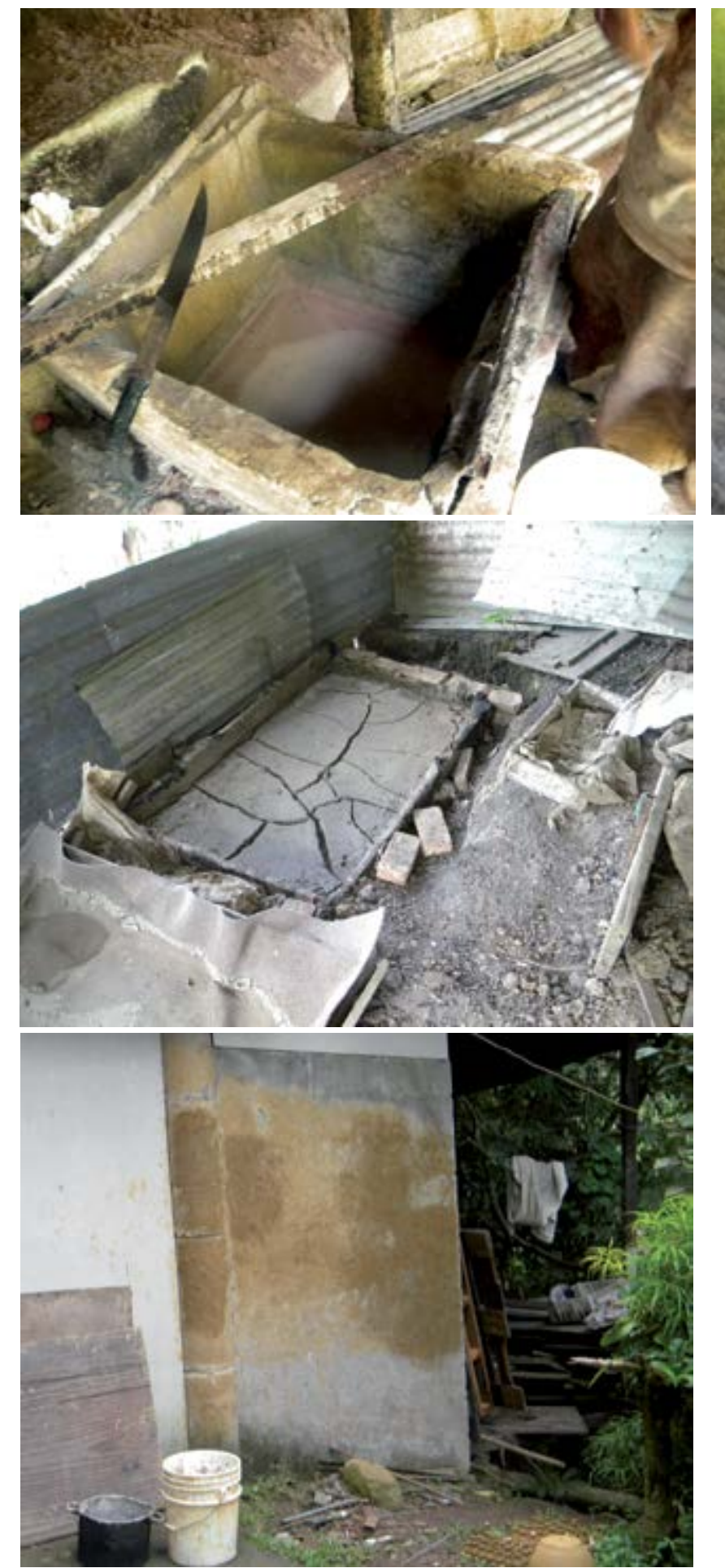

Fotos 2 y 3. Arrib : pailas de depósito de la arcilla. Abajo: cama de
secado y pared dond se coloca la arcilla como general, no es una arcilla muy comercializada en los trabajos de los artesanos en Santa Ana. La preferencia de los ceramistas se refleja en el uso de la arcilla grisácea o barro de olla, o la que presenta tonalidades rojizas. La obtención de la arcilla ultimo paso. terceros; en este caso, el costo será elevado para el artífice.

El barro de olla se utiliza para la creación de piezas pequeñas menores a una taza de café, 0 miniaturas de entre 1 a $3 \mathrm{~cm}$; estas últimas son utilizadas para la decoración de fachadas típicas o como recuerdos. El barro más rojizo se utiliza para elaborar vajillas comunes. platos, tazas, tazones, picheles, ya que, por sus caracteristicas, soporta temperaturas, en el horneado, mas eleDespués de hazer escogido la Después de haber escogido la arcilla adecua"mezclado"; el ceramista, con sus hábiles me mezcla la a illa por 15 minutos para exmanos, mezcla la aciclla por 15 minutos para extraer de zaranda no conture; luego se deja rezosa y se

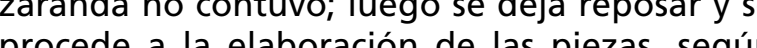
proceno la en la idea del alfasero. to hace cuanto forma yuso, pero que se ha convertido en el sello de los ceramistas. El torno es confeccionado con materiales en madera y hiero; movido por la fuerza del pie, que hace girar una movido por la fuerza del pie, que hacegiraruna no que se pueda llamar estándar entre los alfareros, cada uno adapta su torno a su condición física y a la disposición de este para la facilidad del trabajo. Asimismo, es posible encontrar tornos o tornetas eléctricas, que son vistos como una ayuda en cuanto a la reducción de la fuerza humana necesaria para el trabajo de arcilla.

Otra de las técnicas manejadas por los art

fices en barro, para conformar piezas, as la utices en bán rización de rollos de arcilla de diferentes grosores: esta técnica es poco utilizada en actualidad, sin embargo, se maneja la idea de que esta forma de confeccionar vasijas es un manera básica de creación y que, incluso, fue utilizada en la época precolombina para fuericar piezas de considerable valor estilístico. Para erigir los rollos, se moldea el trozo de barro con las palmas de la mano o, en su defecto, se utiliza un artefacto llamado "estrosora".

La "estrosora" es una herramienta confeccionada con dos tubos PVC; uno de los tubos es más ancho en su diámetro que el otro, estos se
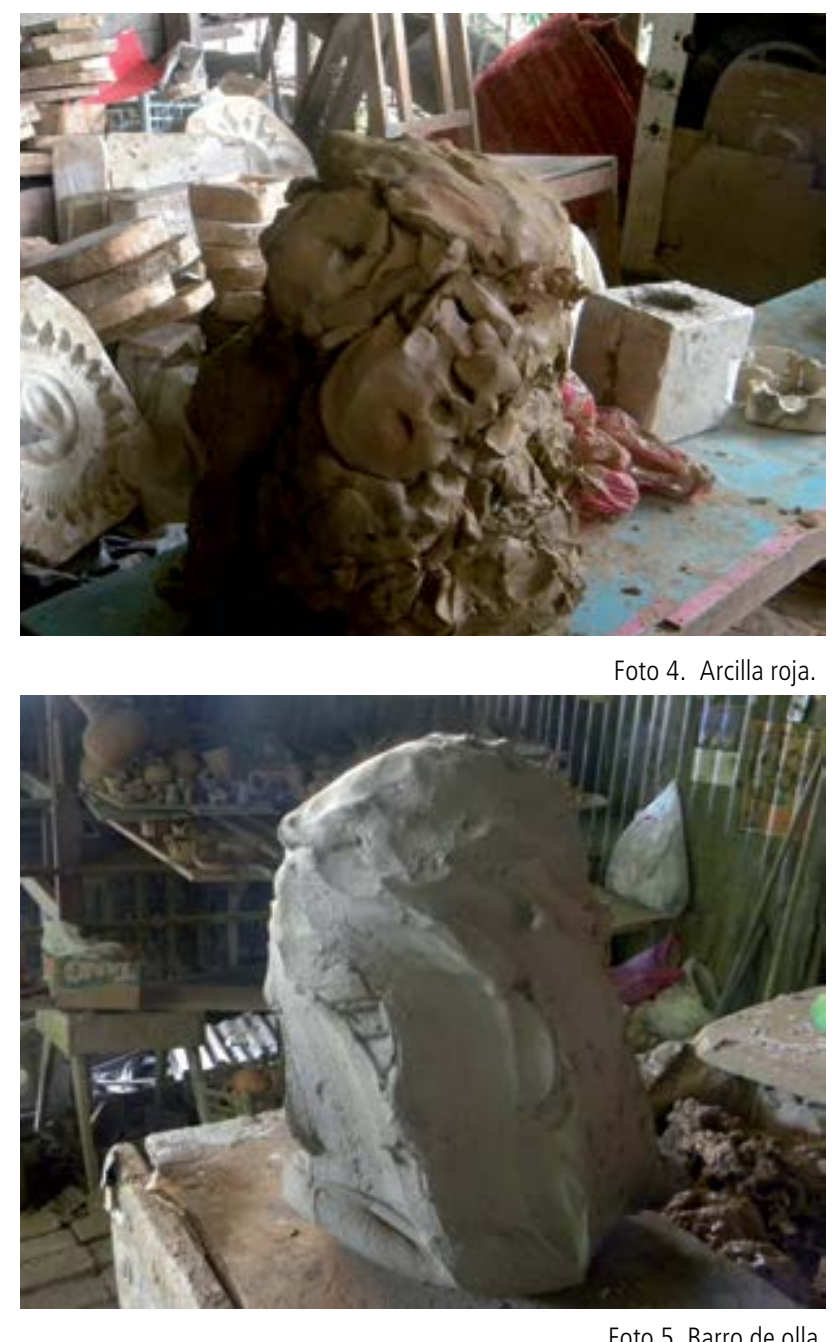

Foto 5. Barro de olla.

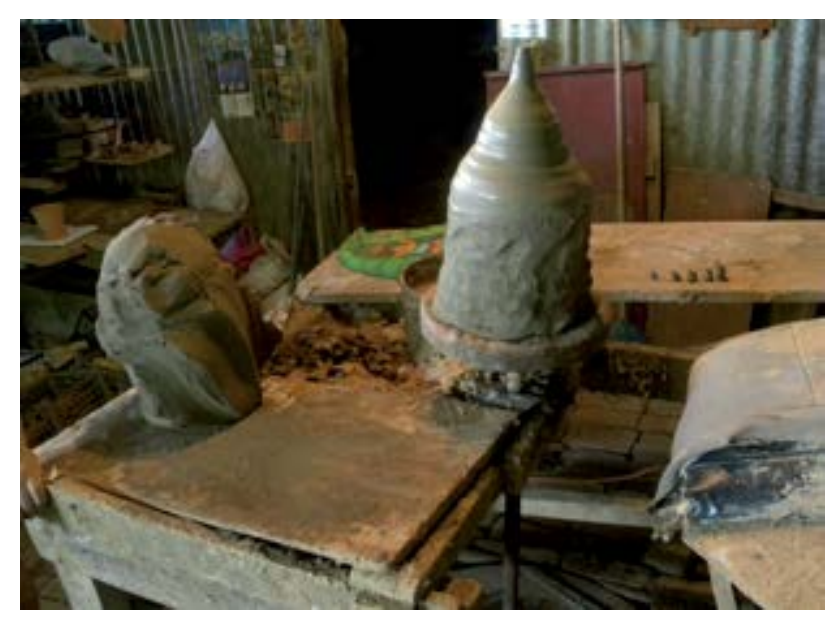

unen para ejercer presión y que salgan los rollos ya formados. Se utiliza, además, un retazo de esponja y varias boquillas (que no son más que tapas de plástico con 


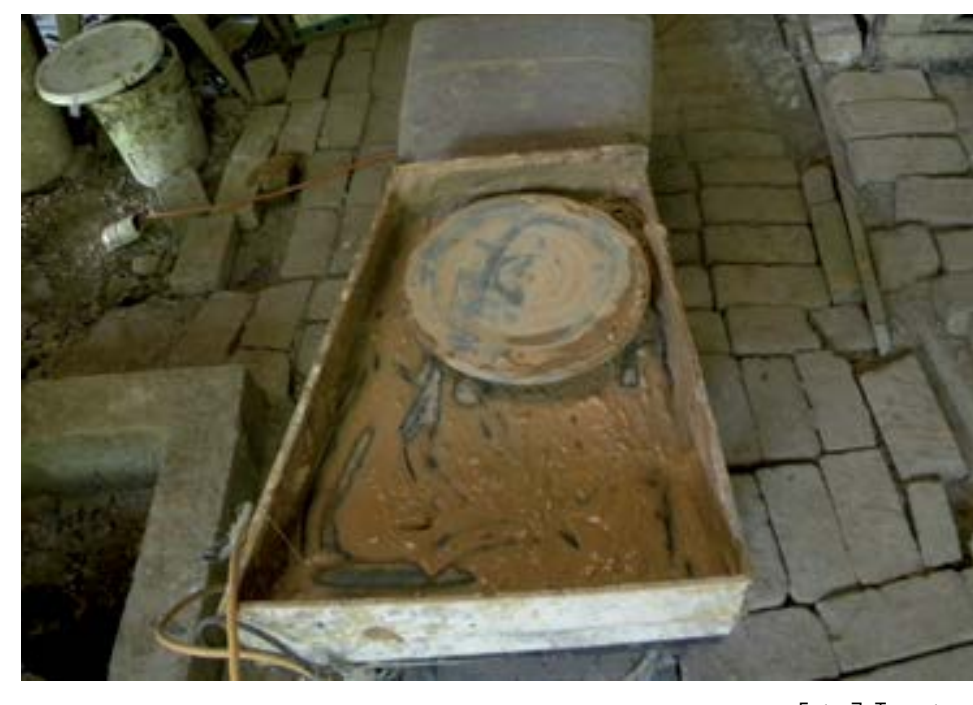

Foto 7. Torneta.
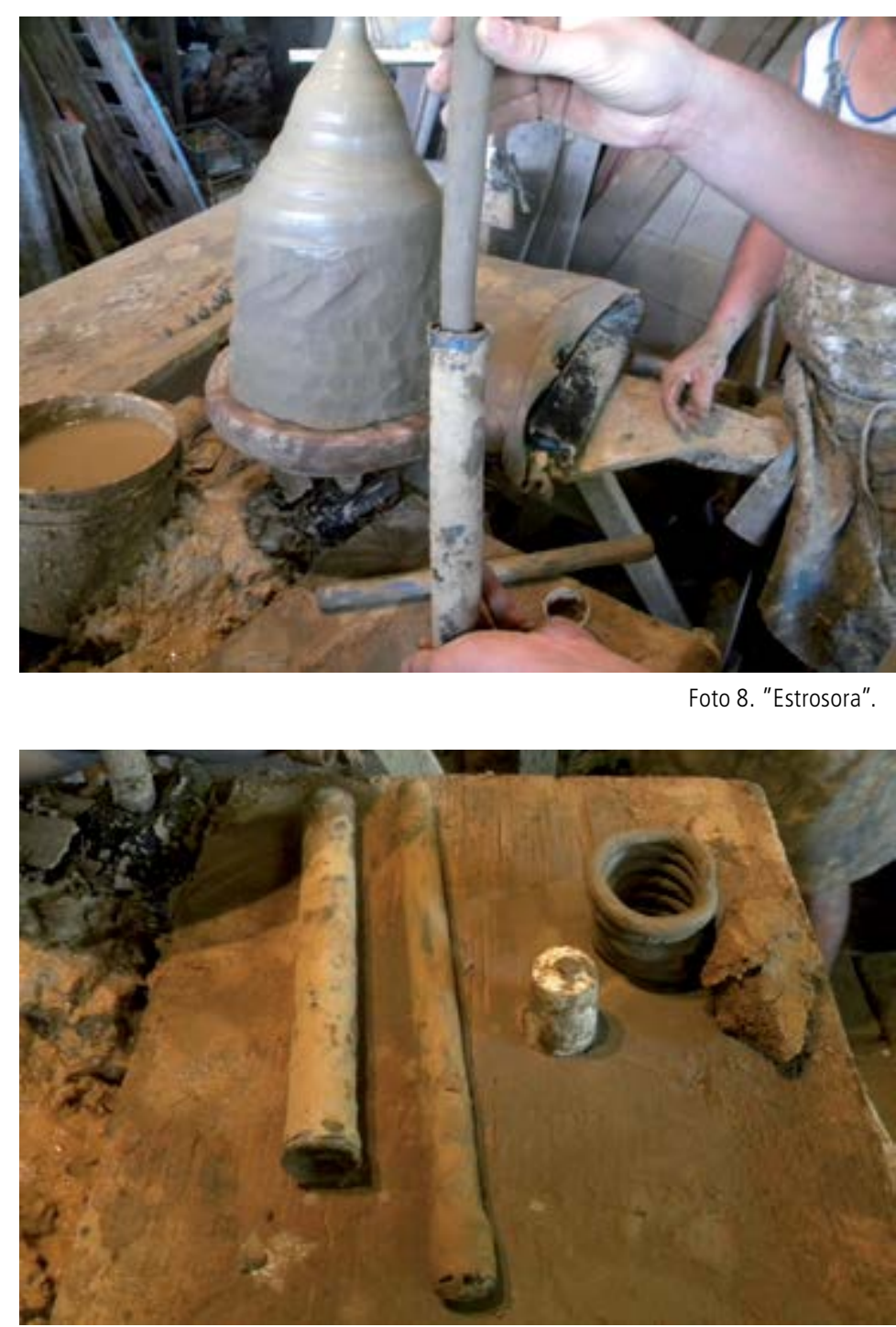

de este artefacto funciona con presión manual; asimismo, se pueden encontrar "estrosoras" más elaboradas, que consisten en un aparato fijado a un mueble donde hay una palanca que facilita el trabajo.

posibilidad de realizar piezas a partir de moldes que los artesanos confeccionan con yeso sobre l prototipo para la reproducción de figuras. Upo para la reproducción de

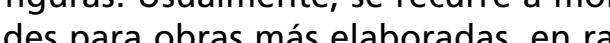
zón de diseños pequeños o complejos, zone de diseñs pequenos o complejos, que con el torno o la "estrosora" no producción más rápida. producción más rapida.

dejan o hasta que la pieza haya tomado un "punto de cuero"; es decir, que ya no se encuentre tan suave y frágil como cuando se moldeó. Estas artesanías, fácilmente, podrían volver a ser barro si se les agregara agua, por lo cual se tiene un cuidado especial al trabajarlas. Cuando la producción de piezas de un número considor de piezas es de al horneado, ya sea en horno tradicional o eléctrico. Muchos artesanos de la zona no cuentan con un horno eléctrico, ya que implica gastos considerables; los artesanos se apegan más al uso convencional del horno elaborado de ladrillo y arcilla, que funcion con leña. El horneado usualmente se hace cada 15 días, dependiendo de cantidad de las obras cerámicas.

En el horno, las piezas de mayor dimensión se colocan en la parte inferior sobre una cama de ladrillos, para que reciban directamente la intensidad de calor; las de menores dimensiones, colocan dentro de otras, para evitar su agrietamiento o destrucción lo que significaría perder el trabajo de varias horas. El horno es precalentado hasta los $400{ }^{\circ} \mathrm{C}$ y luego, muy suavemente el artesano incrementa la temperatura de cocción hasta los $900{ }^{\circ} \mathrm{C}$ o $970{ }^{\circ} \mathrm{C}$ según el tipo de arcilla. Si el horno es calentado súbitamente, se corre el riesgo de que los ceramios exploten y la labor de manufactura se haya realizado en vano. Las piezas se cuecen por alrededor de 4 horas y se cesa de avivar el fuego cuando el horno se vuelve incandescente, lo cual indica que tanto las artesanías como la hornilla cuentan con su temperatura ideal; posteriormente, se deja enfriar a temperatura ambiente. El horno electrico, por sus características, nada asisnedece la graduacion de la temperatura y el tiempode cocción que se le signe mecánicamente.

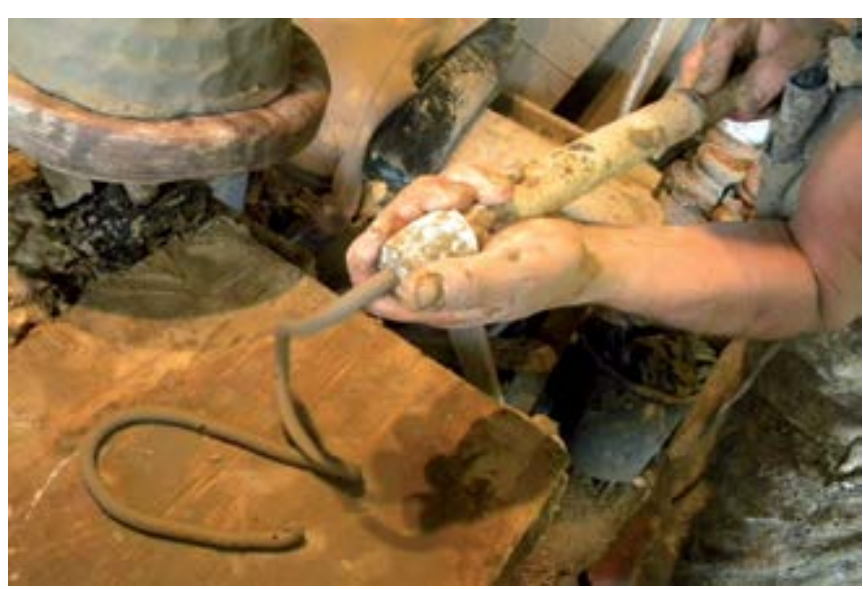

Las obras finales obtenidas por los alfareros presentan una gran variedad de formas y tamacan un esmalte libre de plomo llamado "glade" que le dará a la pieza un brillo muy particular. que le dará a la pieza un brillo muy particular. hornear. La particularidad es que este posthorneado se debe efectuar en un horno póctrico, porque la temperatura debe ser muy regutrico, por lo tanto, muchos artesanos prefieren trabajar la cerámica con un acabado natural.
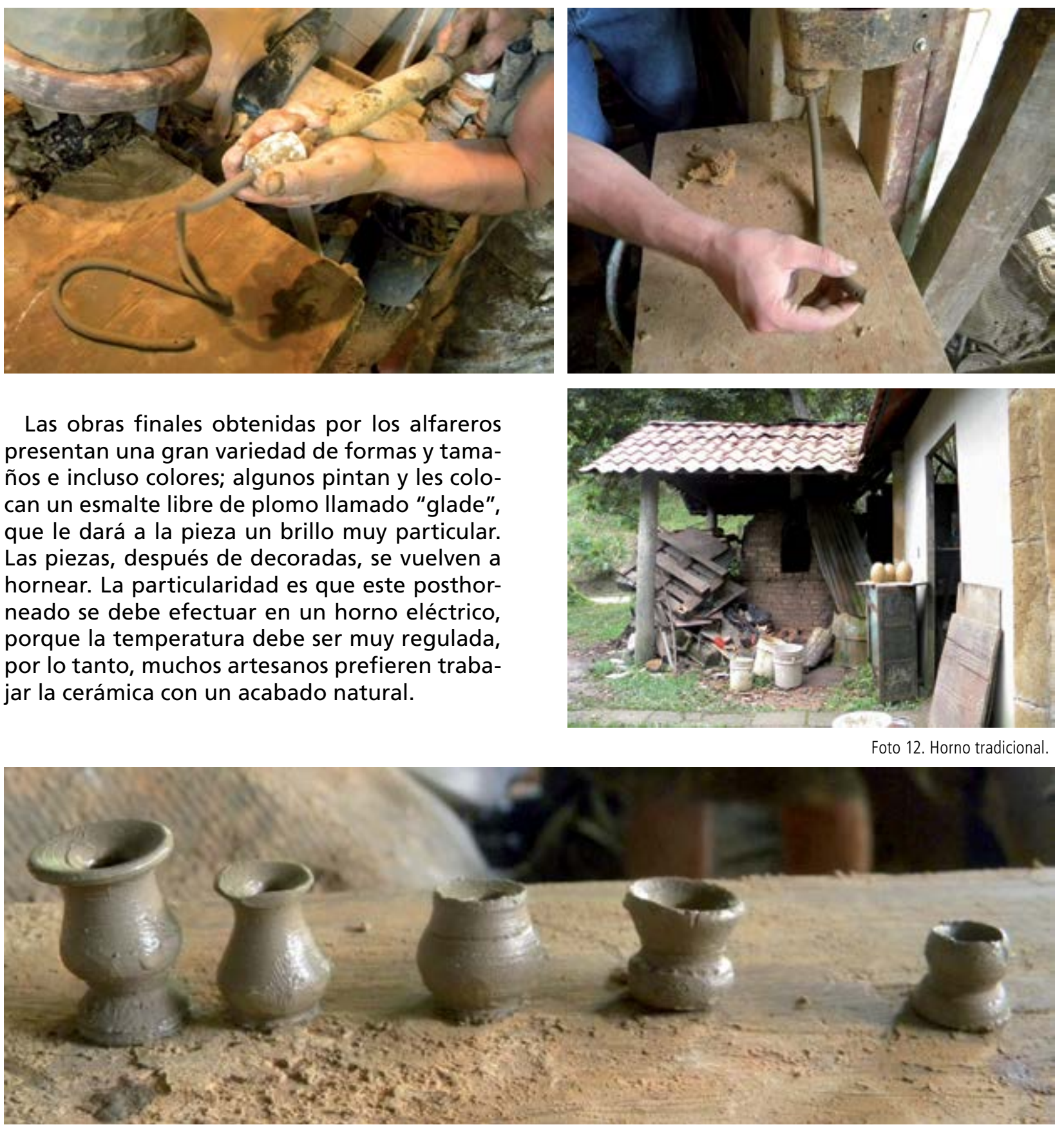

Foto 13. Muestra de piezas. 


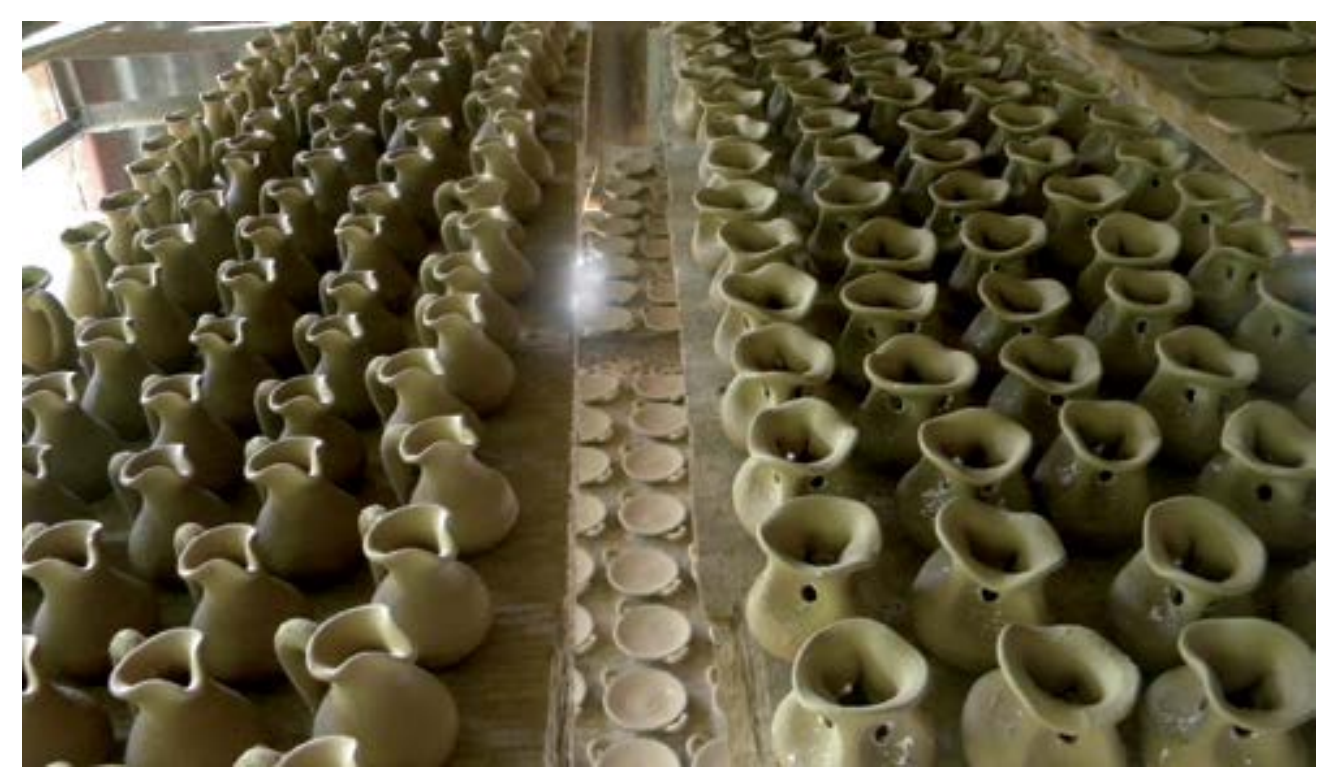

Fotos $14 \mathrm{y} 15$ Muestra de piezas.

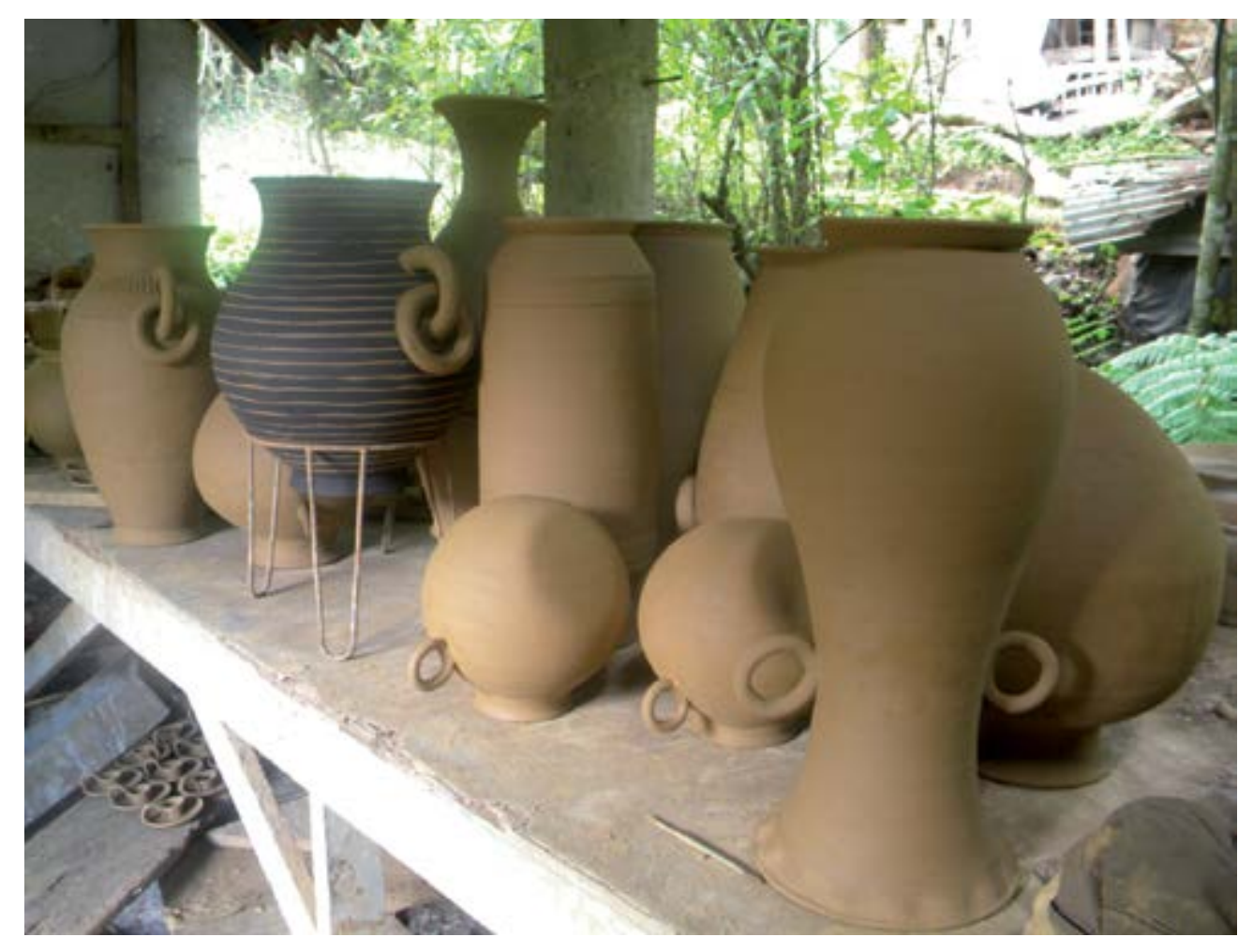

\section{Conclusiones}

La habilidad de los artesanos es indiscutible, y el conocimiento empírico que se ha pasado de generación en generación persiste aun actualmente. Los talleres alfareros se sostienen mayoritariamente con una economía familiar, donde cada dí de los parientes más allegados al alfarero le son de ayuda; sin embargo, que posibiliten que la producción artística tradicional siga adelante.
Otro gran problema, que fue posible observar, es la escasa ayuda por parte de los organismos del gobierno local, específicamente en el tema de ubicación y coexistencia de la labor de los talleres de alfarería con el creciente entorno urbano y de densificación poblacional, asi como el caso de las regulaciones seguidas por el $\mathrm{Mi}$ nisterio de Salud que dificultan la realización de la labor del alfarero que se apega a los metodos tradicionales de producción, o que no puede dejar por condiciones varias. Los artesanos necesitan espacios donde se muestre y fortalezca más su labor y su sustento, porque, al fin y al cabo, estas piezas representan su manera de salir adelante, además de cons.turse en uno de los elementos historico culturales propios de sus comunidades.

La hertesano muestra, a muy grandes rasgos, la facilidad que tiene el ser humano para transformar su entorn

\section{Bibliografía}

Avendaño, Mayela et al. (1982). Sistematización, sobre la situación del grupo de artesanos de cerámica de Santa Ana. Tesis para optar por el grado de licenciatura en Trabajo Social. San José: Universidad de Costa Rica.

Benavidez, Clotilde. (2004). "Reflexiones sobre la formación y función social de los artesanos en Cartago en el Siglo XVIII". Revista Estudios. San José: Escuela de Estudios Generales. Editorial de la Universidad de Costa Rica. Páginas 18-19.

Chang, Guisselle. (2001). "Nuestras artesanías". Serie Culturas Populares Centroamericanas. No. 3. San José: Coordinación educativa y cultural de Centroamérica.

. (2003). "Herramientas y técnicas de los artesanos del Valle Central en el Siglo XVIII". Revista Guasol. No. 5. San José: Escuela de Estudios Generales. tral en el Siglo XVIII". Revista Guasol. No.
Editorial de la Universidad de Costa Rica.

Oliva, Mario. (1985). Artesanos y obreros costarricenses 1880-1914. San José: Editorial de la Universidad de Costa Rica.

Neef, Eva. (1990). Cerámica Precolombina, procesos de Manufactura de artefactos cerámicos monocromos del Valle Central Oriental-Zona Pejivalle. Tesis presentada para optar por el título de Licenciada en Artes Plásticas con énfasis en cerar José: Universidad de Costa Rica.

Rodríguez, Eugenia. (1993). "Proteger lo propio: documento para la historia de la artesanía en la Costa Rica de mediados del siglo XIX". Revista de Historia. No. 28. San José: Editorial de la Universidad de Costa Rica.

\section{Fuentes Electrónicas}

Blanco, Patricia. (2008). "Ladrilleras artesanales se resisten a desaparecer". Revista Presencia Universitaria. San José: Universidad de Costa Rica. Recuperado de: http:// odi.ucr.ac.cr/docs/presencia/revista_presencia_101.pdf 
Payne, Elizet. (2000). “Maestros, oficiales y aprendices: la incipiente organización artesanal en la Cartago del siglo XVII". Revista electrónica de Historia. San José: Universidad de Costa Rica. Recuperado de http://historia.fcs.ucr.ac.cr/dialogos.htm

Schvartz, Analía Ester y Jordán, Carlos Romualdo. (2006). "Modelado en Torno Alfarero: del Artesano Anónimo al Autor". De Artes y Pasiones. Recuperado de www. deartesypasiones.com.ar 